\title{
Effects of the non-indigenous cladoceran Cercopagis pengoi on the lower food web of Lake Ontario
}

\author{
COREY L. LAXSON*, KERRY N. MCPHEDRAN ${ }^{\dagger}$, JOSEPH C. MAKAREWICZ*, IRENA V. TELESH \\ AND HUGH J. MACISAAC ${ }^{\dagger}$ \\ *Department of Environmental Science and Biology, State University of New York at Brockport, Brockport, NY, U.S.A. \\ tGreat Lakes Institute for Environmental Research, University of Windsor, Windsor, Ontario, Canada \\ $\ddagger$ Zoological Institute of the Russian Academy of Sciences, St Petersburg, Russia
}

\section{SUMMARY}

1. In North America, the invasive predatory cladoceran Cercopagis pengoi was first detected in Lake Ontario. We explored the impact of Cercopagis on the lower food web of Lake Ontario through assessments of historical and seasonal abundance of the crustacean zooplankton, by conducting feeding experiments on the dominant prey of the invader, and by estimating its food requirements.

2. Between 1999 and 2001, a decrease in the abundance of dominant members of the Lake Ontario zooplankton community (Daphnia retrocurva, Bosmina longirostris and Diacyclops thomasi) coincided with an increase in the abundance of Cercopagis. Daphnia retrocurva populations declined despite high fecundity in all 3 years, indicating that food limitation was not responsible. Chlorophyll $a$ concentration generally increased, concomitant with a decline in the herbivorous cladoceran zooplankton in the lake.

3. Laboratory experiments demonstrated that Cercopagis fed on small-bodied species including $D$. retrocurva and B. longirostris.

4. Consumption demand of mid-summer populations of Cercopagis, estimated from a bioenergetic model of the confamilial Bythotrephes, was sufficient to reduce crustacean abundance, although the degree of expected suppression varied seasonally and interannually.

5. Predatory effects exerted by Cercopagis on the Lake Ontario zooplankton, while initially very pronounced, have decreased steadily as the species became established in the lake.

Keywords: Cercopagis, food web, Lake Ontario, non-indigenous species, predation

\section{Introduction}

Over the past 15 years the Laurentian Great Lakes, as well as many inland lakes in North America, have experienced a wave of invertebrate invasions from Eurasia (see Ricciardi \& MacIsaac, 2000; Ricciardi, 2001). Unlike exotic species invasions of the Great Lakes in the early twentieth century (Mills et al., 1993), recent invaders became established at low- and mid-

\footnotetext{
Correspondence: Joseph C. Makarewicz, Department of Environmental Science and Biology, State University of New York at Brockport, Brockport, 14420 NY, U.S.A. E-mail: jmakarew@brockport.edu
}

trophic levels and have dramatically altered energy flow and contaminant movement through the lakes (Dermott et al., 1999; Ryan et al., 1999; reviewed in Shuter \& Mason, 2001). The most recent invader to establish itself in Lake Ontario is the predaceous zooplankter Cercopagis pengoi (Ostroumov) (MacIsaac et al., 1999; Makarewicz et al., 2001a). Within 3 years of being reported in Lake Ontario, C. pengoi invaded Lake Michigan (Charlebois, Raffenberg \& Dettmers, 2001) and Lake Erie (Therriault et al., 2002), as well as many inland lakes in New York (e.g. Seneca, Cayuga, Otisco, Canandaigua, Owasco and Cross) and Michigan (e.g. Muskegon) (Makarewicz et al., 2001a; Therriault et al., 2002).

(C) 2003 Blackwell Publishing Ltd 
Cercopagis pengoi is now one of the most abundant predaceous zooplankters in Lake Ontario, although its maximum offshore density has decreased each year since colonisation from a mean peak abundance of $1759 \mathrm{~m}^{-3}$ in 1999 to $355 \mathrm{~m}^{-3}$ in 2001 (Makarewicz et al., 2002). In general, Cercopagis appears in the zooplankton community at low density $\left(<30 \mathrm{~m}^{-3}\right)$ in late June and does not achieve maximum abundance until late July. Peak abundance at both nearshore and offshore sites in Lake Ontario occurs between late July and mid-August (Makarewicz et al., 2002). Two closely related forms, C. pengoi and C. ossiani, occur in Lake Ontario (Makarewicz et al., 2001a). Sequencing of the mitochondrial ND5 gene revealed that these forms are characterised by a single haplotype, and that only the ancestral species, C. pengoi, is actually established in the lake (Makarewicz et al., 2001a). The morphotypes probably represent progeny produced via sexual (C. ossiani) and asexual reproduction (C. pengoi) (Simm \& Ojaveer, 1999; Makarewicz et al., 2001a). Similar morphological differences have been reported for confamiliar Bythotrephes (Zozulya, 1977; Yurista, 1992).

Cercopagis pengoi is a predatory cladoceran that preys on zooplankton by physically tearing the integument of the prey and ingesting the contents (Mordukhai-Boltovskoi, 1968). Rivier (1998) inferred that $C$. pengoi fed on nauplii, copepodids and adult calanoid copepods. Field evidence from Lake Ontario demonstrated that invasion by $C$. pengoi was correlated with the decline in abundance of juvenile cyclopoids in the epilimnion (Benoit et al., 2002). Research on the confamilial Bythotrephes provides insight on the possible impacts that $C$. pengoi might have on the food web. For example, in Harp Lake, Ontario, long-term analyses of zooplankton community structure preand post-Bythotrephes invasion revealed a significant decline in crustacean zooplankton diversity, particularly of small-bodied taxa (Dumitru, Sprules \& Yan, 2001; Yan, Girard \& Boudreau, 2002). Similarly, smalland mid-sized Daphnia spp. declined after invasion of Lake Michigan by Bythotrephes (Lehman \& Caceres, 1993). Schulz \& Yurista (1999) suggested that Bythotrephes preferred larger prey [e.g. Daphnia pulicaria (Forbes)], while the smaller $C$. pengoi would probably be limited to consumption of smaller species by virtue of its smaller size. Because small-bodied cladocerans and cycloploid copepods have historically dominated the zooplankton community of Lake Ontario, invasion by C. pengoi may be expected to impact zooplankton diversity and community composition ( $\mathrm{O}^{\prime}$ Gorman, Bergstedt \& Eckert, 1987; Johannsson, Mills \& O'Gorman, 1991; Lampman \& Makarewicz, 1999).

The goal of this study was to identify the predatory impact of $C$. pengoi on lower trophic levels of the Lake Ontario community by combining studies of seasonal and historical abundance of the zooplankton and phytoplankton, laboratory studies on feeding, and bioenergetic estimates of consumption requirements.

\section{Methods}

\section{Seasonal field sampling}

Procedures and locations for sampling the zooplankton followed Makarewicz et al. (2001a). In general, samples were taken due north of Hamlin Beach State Park ( $43^{\circ} 25.110^{\prime}$ latitude and $77^{\circ} 53.986^{\prime}$ longitude), Lake Ontario, New York, U.S.A. Samples were collected from two stations (30- and 100-m depth) between 07.00 and 10.00 hours. Diel studies indicated that $C$. pengoi did not migrate below $20 \mathrm{~m}$. Sampling was conducted every 2 weeks in spring and autumn and weekly during the summer when $C$. pengoi abundance increased.

Zooplankton samples were collected using vertical hauls taken from $20 \mathrm{~m}$ to the surface. Cercopagis pengoi was collected using a flow-metered double Bongo net (571- $\mu \mathrm{m}$ mesh net, $50-\mathrm{cm}$ diameter). The entire sample was counted because of the tendency of $C$. pengoi spines to tangle, which would have prevented unbiased subsampling. The remainder of the zooplankton community was collected using a Wisconsin net (63- $\mu \mathrm{m}$ mesh net, $50-\mathrm{cm}$ diameter) equipped with a flow meter. Both samples were preserved in $10 \%$ buffered formalin. Before counting, zooplankton samples were mixed thoroughly and diluted individually to obtain 150-350 organisms per subsample. Three replicate $10-\mathrm{mL}$ subsamples were withdrawn using a Hensen-Stemple pipette. Zooplankton taxonomy largely followed Balcer, Korda \& Dodson (1984) although other keys were also consulted (e.g. Edmondson, 1959; Rivier, 1998). Cladocerans, adult cycloploid copepods and large rotifers were identified, and the number of individuals and eggs per species were counted using a dissecting microscope and a multichambered glass counting cell (Gannon, 1971). Length measurements were made on the first 20 
individuals of each species encountered per sample. Calanoid copepods, cycloploid nauplii and copepodids were counted but not identified to species. Historical abundance data were analysed with the non-parametric comparison ANOVA method of Kruskal-Wallis followed by a multiple comparison test (Dunn's Test, see Siegal \& Castellan, 1988; Zar, 1999).

Phytoplankton samples were collected with a water bottle in August 2000 at a depth of $3 \mathrm{~m}$ and immediately preserved with Lugol's iodine and formalin solution. Counting procedures followed Makarewicz, Bertram \& Lewis (1998).

During 2001, the vertical distribution of potential prey items of $C$. pengoi was established at the offshore location by performing zooplankton tows at fixed depth intervals $(0-20,20-40$, and $40-60 \mathrm{~m})$ with a closing net (17-cm diameter, $63-\mu \mathrm{m}$ mesh) equipped with a flow meter. The diel distribution of zooplankton was assessed by collecting replicate $(n=3)$ samples at $1-\mathrm{m}$ intervals from the surface to $20 \mathrm{~m}$ between 1300 and 1400 and between 2200 and 2330 on 27 July 2001. Samples were collected, using a submersible water pump at a rate of $1 \mathrm{~L} \mathrm{sec}^{-1}$ into filter tubes (0.3-m length and $12-\mathrm{cm}$ diameter, $153-\mu \mathrm{m}$ mesh net). Samples were counted in entirety for $C$. pengoi and for D. retrocurva (Forbes). The Kolmogorov-Smirnov test, which is sensitive to differences in the general shapes of two distributions, was used to evaluate diel differences in zooplankton abundance.

\section{Laboratory feeding experiments}

Laboratory feeding experiments, using C. pengoi collected daily at Hamilton Harbour, were conducted on the two dominant cladocerans in Lake Ontario. Short net hauls (210- $\mu \mathrm{m}$ mesh, $0.5-\mathrm{m}$ diameter) were used to collect zooplankton, which were rinsed into 1.5-L containers containing lake water to minimise stress during transport to the laboratory. Free (i.e. spine unattached to conspecifics or detritus) and apparently healthy (i.e. swimming well) C. pengoi individuals were isolated and removed from samples using either a wide mouth pipette or fine forceps and placed singly within an environmental chamber containing filtered lake water (Whatman glass microfibre $934 \mathrm{AH}$ filter, $1.5-\mu \mathrm{m}$ ) for a 24-hour acclimation period (Yurista \& Schulz, 1995). Prey species [Bosmina longirostris (Muller) and $D$. retrocurva)] were also collected from Hamilton Harbor, Lake Ontario. Individual prey species separated into monocultures were placed into 2-L containers filled with aerated, filtered lake water and fed dried Chlorella daily $\left(<1 \mathrm{mg} \mathrm{L}^{-1}\right)$. Every second day, prey monoculture water volumes were reverse filtered to $25 \%$ of the total initial volume using a $40-\mu \mathrm{m}$ Nitex mesh filter and brought back up to volume with the addition of freshly-collected, filtered lake water.

Experiments were conducted in an environmental chamber at $18{ }^{\circ} \mathrm{C}$ and $1.78 \mu \mathrm{E} \mathrm{m}^{-2} \mathrm{~s}^{-1}$ light intensity (24-hour light) using third instar, parthenogenic females of $C$. pengoi in $1.5-\mathrm{L}$ vessels. Within the environmental chamber, experimental containers were placed in an open-top box allowing only diffuse overhead light. Healthy prey (40 per vessel, $n=5$ ) were randomly added to containers filled with filtered lake water and a single $C$. pengoi. Prey density $\left(26000 \mathrm{~m}^{-3}\right)$ approximated the average total zooplankton abundance observed in western Lake Ontario in 2000. Replicated controls lacking C. pengoi were also run for each treatment. After $12 \mathrm{~h}$, the contents were concentrated by reverse filtration (using 40- $\mu \mathrm{m}$ Nitex mesh) and observed using a dissecting microscope to assess predator and prey mortality, as well as animal condition. Prey individuals found trapped within the water surface film were considered as live after the experimental period.

\section{Energetic requirements of Cercopagis}

Cercopagis pengoi and Bythotrephes are confamilial and have similar morphological features, feeding behaviours and ecological niches. Both species grab prey with enlarged antennae and physically tear the integument and ingest the contents of prey organisms (Mordukhai-Boltovskoi, 1968; Rivier, 1998). Owing to the paucity of physiological data and the similarity in feeding behaviour, a bioenergetics model developed for Bythotrephes (Yurista \& Schulz, 1995) was employed to estimate C. pengoi consumption demand. With appropriate model adjustments based upon the proportional body mass of the two species, the model assumed that, like third instar Bythotrephes, third instar Cercopagis will consume $105 \%$ of its dry weight in carbon per day. Consumption rates, particularly of predators, approach or exceed $100 \%$ of dry weight per day for several species (Yurista \& Schulz, 1995). For example, the copepod Mesocyclops edax (Forbes) consumed $100 \%$ of its dry weight per day (Brandl \& 
Fernando, 1975) and Polyphemus, a predatory cladoceran closely related to Cercopagis and Bythotrephes, consumed $86 \%$ of its dry weight per day (Monakov \& Sorokin, 1972). Bosmina, a herbivore, may consume as much as $170 \%$ per day at high food concentrations (Urabe, 1991).

The number of prey required to fulfill the energetic demand of a single $C$. pengoi (predation rate) was calculated by dividing the consumption demand $\left(\mu \mathrm{gC}\right.$ day $\left.^{-1}\right)$ by the mean weight, in carbon, of prey. Zooplankton weights were calculated by utilising the median lengths and the associated length : weight regressions for Great Lakes zooplankton of Culver et al. (1985), as well as length : weight relationships for Lake Ontario populations of D. retrocurva, B. longirostris and D. thomasi (Forbes) (Johannsson \& O'Gorman, 1991) and Cercopagis (Makarewicz et al., 2001b). Carbon was assumed to make up 50\% of dry weight (Salonen et al., 1976; Makarewicz \& Likens, 1979).

To evaluate further the impact of $C$. pengoi on the zooplankton in Lake Ontario, an alternate approach, using the physiological method of Winberg assessed predation pressure as the relationship between consumption rate of $C$. pengoi $\left(C_{i}\right)$ and production rate of its potential prey $\left(P_{\mathrm{hz}}\right)$ (Telesh, Bolshagin \& Panov, 2001). Predation pressure $\left(C_{i} / P_{\mathrm{hz}}\right)$ exerted by the C. pengoi population at peak abundance was considered as a measure of the per capita effect of the invader on the plankton. The overall impact $(I)$ of $C$. pengoi on the zooplankton in Lake Ontario in 1999 through 2001 was calculated as:

$$
I=\left(N_{i} / N_{z}\right)\left(C_{i} / P_{\mathrm{hz}}\right) \text {, }
$$

where $N_{i} / N_{z}$ is the relation of population density of C. pengoi $\left(N_{i}\right)$ to total crustacean zooplankton abundance $\left(N_{z}\right)$. The parameter $(I)$ is a dimensionless value which can vary in the range $0 \leq I \leq 1$ (Telesh et al., 2001).

Daphnia retrocurva and B. longirostris production in the upper $20 \mathrm{~m}$ was estimated by the egg-ratio method (Paloheimo, 1974) using the egg development-temperature relationship from Belehradeks's equation (Cooley, Moore \& Geiling, 1986). Production for each species was calculated by multiplying the number of new recruits during the interval between sampling periods $(B)$ by the mean dry weight for individuals of each species during the same period. Individual weight was calculated with the length: weight relationship derived for Lake Ontario taxa (Johannsson \& O'Gorman, 1991). Estimates of $D$. thomasi production followed the empirical model that Shuter \& Ing (1997) developed, in part, with data from Lake Ontario. The model emphasises that the temperature experienced by the organism can account for variation in daily weight-specific production (production : biomass ratio). The biomass of $D$. thomasi on each sampling day was calculated by summing the biomass of each development stage. Mean individual weight for each stage was assumed constant at $0.9 \mu \mathrm{g}$ for nauplii, $1.9 \mu \mathrm{g}$ for copepodids and $3.2 \mu \mathrm{g}$ for adults (Johannsson \& O'Gorman, 1991).

To assess other effects of Cercopagis on the lower food web of Lake Ontario, we measured chlorophyll $a$ concentration. In 1999, between 500- and 750-mL aliquots of water were filtered through a glass-fibre filter; the chlorophyll was extracted with $90 \%$ alkaline acetone (Wetzel \& Likens, 1994) and measured with a Turner Model 111 fluorometer (Turner Instrument Company, Carpinteria, CA, U.S.A.). During 20002001, chlorophyll $a$ concentration and temperature were measured with a Seabird SEALOGGER CTD (Model SBE 25, SeaBird, Inc., Bellevue, WA, U.S.A.) equipped with a WETStar fluorometer (standard range 0.03-75 $\mu \mathrm{g} \mathrm{L}^{-1}$ ). The WETStar fluorometer (Wetlabs, Philomath, OR, U.S.A.) was factory calibrated and confirmed with the Turner Model 111 in the laboratory. Chlorophyll measurements taken with the SeaBird CTD were averaged from $20 \mathrm{~m}$ to the surface.

\section{Results}

From July until September 2001, the numerically dominant cladocerans, $B$. longirostris and $D$. retrocurva, were found predominantly ( 88 and $92 \%$, respectively) in the upper $20 \mathrm{~m}$, while $42 \%$ of adult $D$. thomasi were observed there (Table 1). Juvenile copepodids were also predominantly (70\%) observed in the upper $20 \mathrm{~m}$ of the lake.

The dominant zooplankters displayed different patterns of vertical distribution over the course of a day. Night and day distributions of Daphnia and Cercopagis were significantly different $(P \leq 0.05$, Kolmogorov-Smirnov test). For example, Daphnia was restricted to the epilimnion at night, with a maximum abundance at $8 \mathrm{~m}$ (Fig. 1); at midday its maximum abundance was observed at $12 \mathrm{~m}$ (i.e. below the thermocline). Conversely, maximum C. pengozi 
Table 1 Vertical distribution of potential Cercopagis pengoi prey from July to September 2001. Values represent the percent of the population observed in the top $20 \mathrm{~m}$ of Lake Ontario of the $60 \mathrm{~m}$ sample

\begin{tabular}{|c|c|c|c|c|c|c|}
\hline \multirow[b]{2}{*}{ Date } & \multirow[b]{2}{*}{$\begin{array}{l}\text { Epilimnion } \\
\text { thickness (m) }\end{array}$} & \multirow[b]{2}{*}{$\begin{array}{l}\text { Cercopagis pengoi } \\
\left(\text { Number } \mathrm{m}^{-3} \text { ) }\right.\end{array}$} & \multicolumn{4}{|c|}{ Percent of individuals in the upper $20 \mathrm{~m}$} \\
\hline & & & $\begin{array}{l}\text { Bosmina } \\
\text { longirostris }\end{array}$ & $\begin{array}{l}\text { Daphnia } \\
\text { retrocurva }\end{array}$ & $\begin{array}{l}\text { Diacyclops } \\
\text { thomasi }\end{array}$ & Copepodids \\
\hline 17 July & 2.0 & 0.8 & 97.4 & 94.5 & 57.0 & 94.0 \\
\hline 25 July & 15.0 & 16.3 & 97.4 & 100.0 & 40.4 & 83.0 \\
\hline 1 August & 3.0 & 3.9 & 74.6 & 82.1 & 28.2 & 68.5 \\
\hline 8 August & 12.0 & 354.0 & 60.7 & 84.4 & 7.4 & 26.0 \\
\hline 15 August & 6.6 & 188.0 & 97.2 & 98.0 & 78.0 & 92.0 \\
\hline 28 August & 7.3 & 16.6 & 99.3 & 99.3 & 84.0 & 99.0 \\
\hline 5 September & 22.0 & 3.4 & 81.6 & 87.8 & 4.7 & 42.0 \\
\hline 12 September & 26.0 & 0.6 & 96.2 & 92.4 & 33.0 & 57.0 \\
\hline Average & 11.7 & 72.3 & 88.0 & 92.3 & 41.6 & 70.2 \\
\hline
\end{tabular}

abundance occurred in the epilimnion, with peak abundances at noon and midnight only $1 \mathrm{~m}$ apart (i.e. 5 and $6 \mathrm{~m}$, respectively).

Historically, the crustacean zooplankton community of Lake Ontario has been composed chiefly of small cladocerans and cycloploid copepods, with the summer community dominated by $D$. retrocurva, $B$. longirostris and D. thomasi. While the abundance of these three species in offshore waters varied across years, each has experienced a major decline following establishment of $C$. pengoi in the lake (Fig. 2). For example, mean August abundances of each species were significantly lower $(P \leq 0.05$, Kruskal-Wallis ANOVA) during the 1999 through 2001 interval than during 1986-91 and 1990-95 (Fig. 2).

Seasonal patterns of abundance also support the hypothesis of zooplankton suppression by Cercopagis. Dramatic declines in three common members of the zooplankton community were coincident with peak abundance of $C$. pengoi (Figs 3 and 4). For example, during the summer of 1999, the abundance of $C$. pengoi at the offshore location increased quickly in late July and reached a maximum of $1759 \mathrm{~m}^{-3}$ on 19 August (Fig. 3). Daphnia retrocurva achieved a peak abundance of $4650 \mathrm{~m}^{-3}$ on 30 July and declined sharply to $120 \mathrm{~m}^{-3}$ during the $C$. pengoi population maximum. The decline in Daphnia abundance was not attributable to food limitation, as its instantaneous birth rate did not decline during this time (Table 2). In the week following the $C$. pengoi peak, however, D. retrocurva abundance increased steadily, culminating in a maximum of $5170 \mathrm{~m}^{-3}$ on 9 October. Bosmina longirostris achieved its greatest abundance of $32000 \mathrm{~m}^{-3}$ on 7 July and steadily decreased to $125 \mathrm{~m}^{-3}$ during the C. pengoi population maximum. Unlike Daphnia, however, Bosmina abundance did not rebound following the

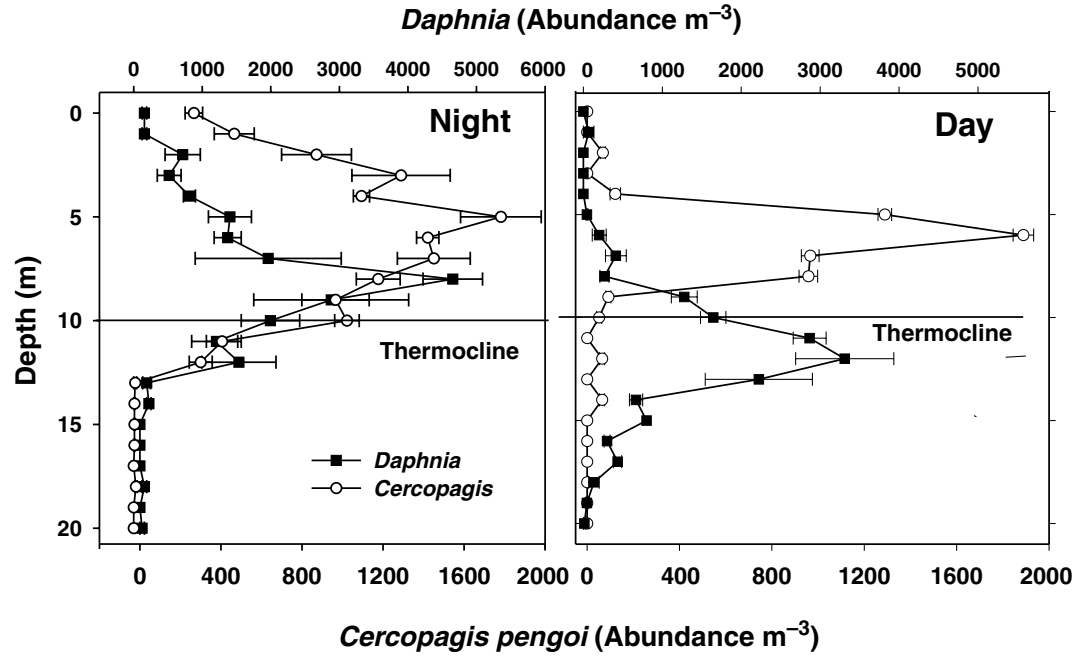

Fig. 1 Vertical distribution of Daphnia retrocurva and Cercopagis pengoi in Lake Ontario during the day (13.00 to 14.00 hours) and night (22.00 to 22.30 hours), 27 July 2001. 


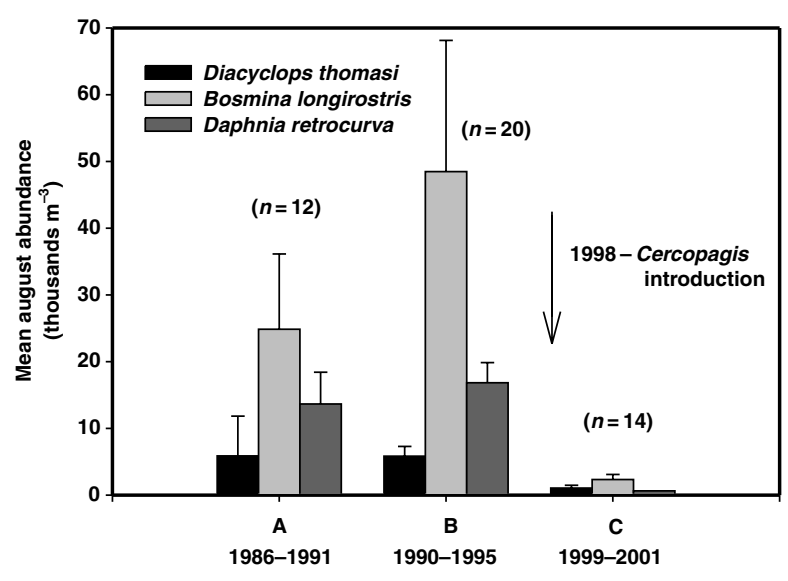

Fig. 2 Average (+1 SE) August abundance of three dominant zooplankton before and after the appearance of Cercopagis in Lake Ontario. Data sources: 1986-91, 100-m site from Makarewicz (1991), 1990-95 from Johannsson et al. (1998) and 19992001, 100-m site from this study. The 1986-91 study and the present study employed the same sampling equipment and technique, including the same sampling locations, depth $(0-$ $20 \mathrm{~m})$, mesh net $(64 \mu \mathrm{m})$, sampling time and sampling months. The 1990-95 of Johannsson et al. (1998) data also represent offshore data taken with a Wisconsin net (0.5-m diameter, $65-\mu \mathrm{m}$ mesh) on the north side of Lake Ontario (sampling depth of 0 $20 \mathrm{~m}$ during unstratified periods or $1 \mathrm{~m}$ above the thermocline to the surface).

decrease of $C$. pengoi. The instantaneous birth rate of Bosmina was below the replacement rate prior to, during, and after the $C$. pengoi population increase
(Table 2). Diacyclops thomasi (adults + juveniles) abundance in the upper $20 \mathrm{~m}$ steadily decreased from a maximum in spring to a minimum in August. Diacyclops abundance increased during autumn and reached nearly $10000 \mathrm{~m}^{-3}$ at the end of the sampling season. Declines in zooplankton abundance at the nearshore station were similar to those at the offshore station in both time and magnitude, despite a $300 \%$ difference in C. pengoi abundances at these locations (Fig. 4).

The inverse patterns of abundance observed between Cercopagis and the three dominant zooplankton taxa during 1999 were largely repeated in 2000 and 2001. During 2000, dominant zooplankton species were in decline or at low abundance whenever Cercopagis density exceeded approximately $200 \mathrm{~m}^{-3}$ (Figs 3 and 4). For example, D. retrocurva abundance remained low $\left(<600 \mathrm{~m}^{-3}\right)$ at the nearshore and offshore sites when Cercopagis was abundant, despite relatively high birth rates (e.g. Table 2). When Cercopagis decreased, D. retrocurva increased (Figs 3 and 4). Similarly, the abundance of Bosmina (nearshore and offshore) and Diacyclops (offshore only) peaked before and after the summer increase in Cercopagis.

During 2001, the density of C. pengoi offshore was significantly lower than in the previous 2 years $(P \leq 0.05$, Kruskal-Wallis ANOva). In contrast, the 2001 nearshore density of $C$. pengoi was not significantly lower than in 1999 and $2000 \quad(P=0.42$,
Fig. 3 Seasonal abundance of Cercopagis pengoi, Daphnia retrocurva, Bosmina longirostris and Diacyclops thomasi in the upper $20 \mathrm{~m}$ at offshore stations of Lake Ontario, 1999 to 2001. Values are mean abundance \pm SE. Horizontal dotted line indicates time period when consumption (bioenergetic estimates) demands of Cercopagis $\left(\mu \mathrm{gC} \mathrm{m}^{-3}\right.$ day $^{-1}$ ) surpass production by each species.

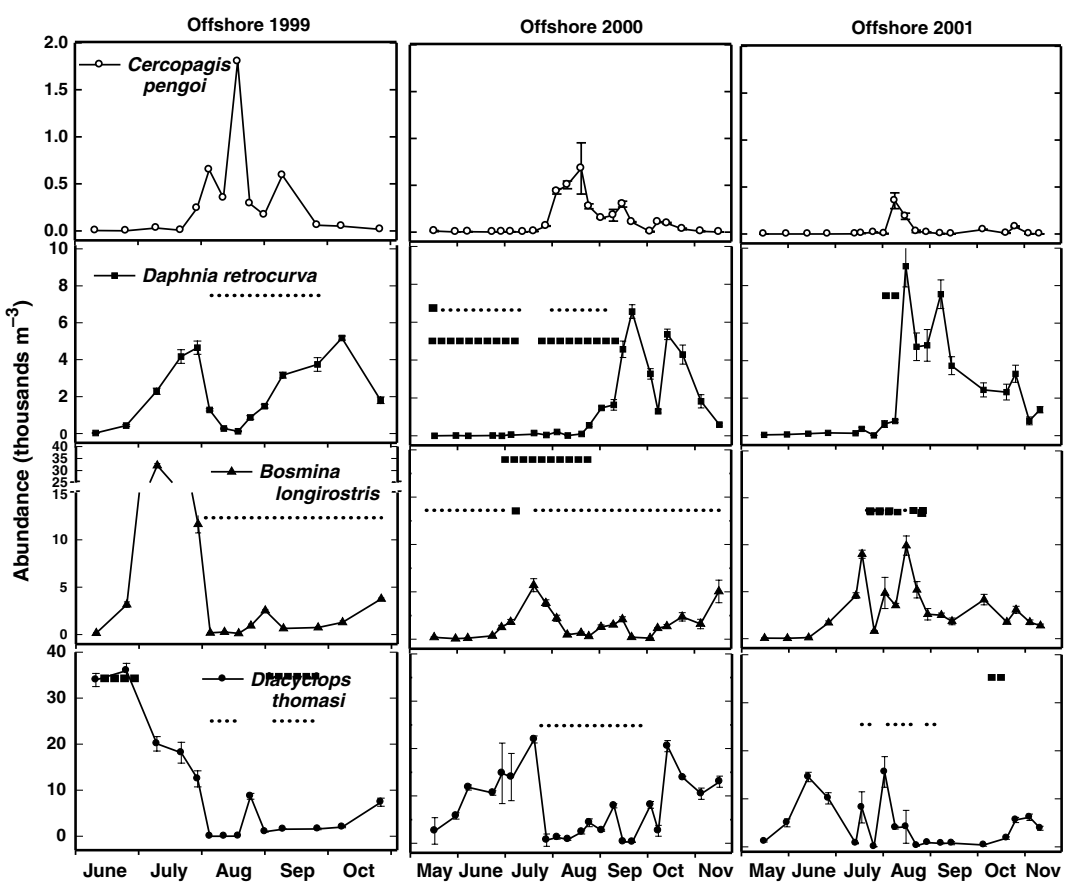




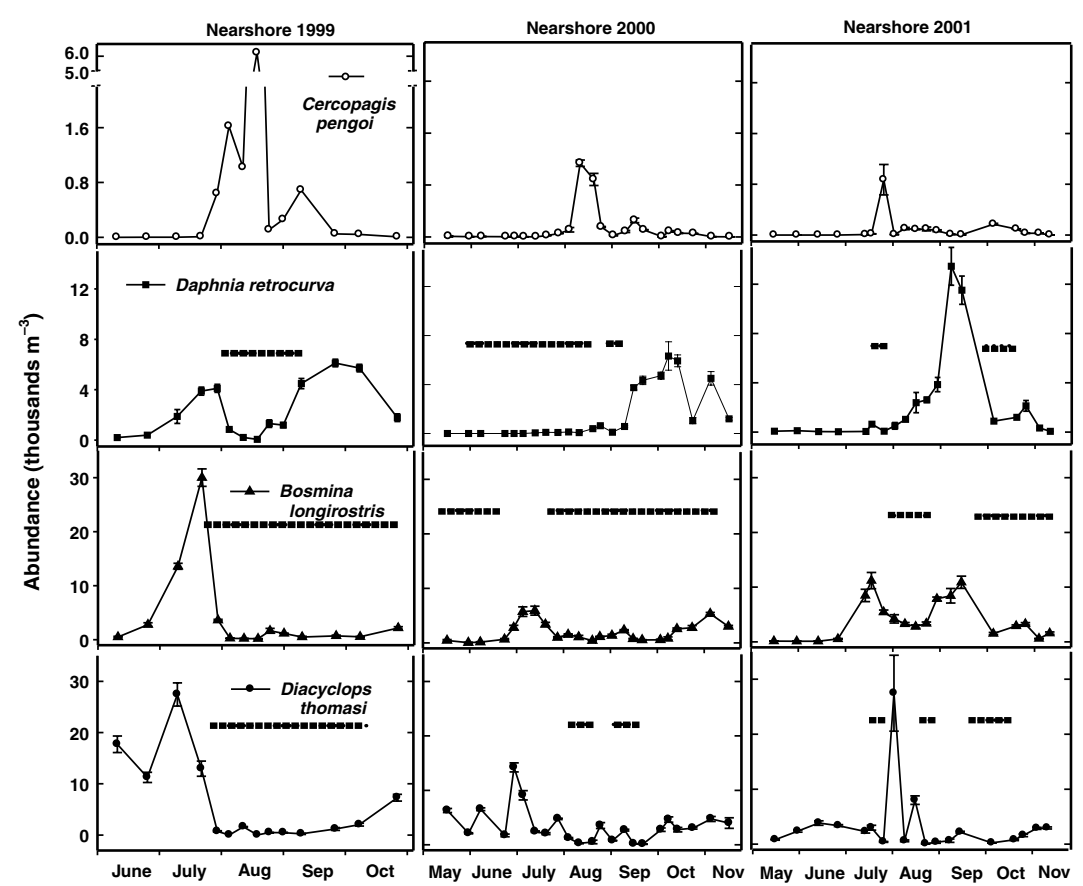

Fig. 4 Seasonal abundance of Cercopagis pengoi, Daphnia retrocurva, Bosmina longirostris and Diacyclops thomasi in the upper $20 \mathrm{~m}$ at nearshore stations of Lake Ontario, 1999-2001. Values are mean abundance \pm SE. Horizontal dotted line indicates time period when consumption (bioenergetic estimate) demands of Cercopagis $\left(\mu \mathrm{gC} \mathrm{m}^{-3}\right.$ day $^{-1}$ ) surpass production by each species.
Kruskal-Wallis ANOva) despite much lower peak densities. Despite a relatively high birth rate over the whole summer period (Table 3), the population of D. retrocurva did not increase markedly until the week after the $C$. pengoi population maximum (Fig. 3). At the nearshore site, $D$. retrocurva began a slow increase in abundance after the peak in Cercopagis abundance (Fig. 4). As in 2000, Bosmina density was lower during the period when Cercopagis was abundant and consumption exceeded production. No obvious relationship existed between Cercopagis and Diacyclops abundance in 2001.

An inverse relationship was observed between the abundance of herbivorous cladocerans, mainly $D$. retrocurva and B. longirostris, and chlorophyll $a$ concentration. This relationship was stronger in 1999 $(r=-0.69, P=0.01)$ and $2000(r=-0.59, P<0.01)$ than during $2001(r=-0.10, P=0.70)$. The highest chlorophyll concentration occurred during algal blooms in late spring and during the mid-summer depression of the herbivorous Cladocera associated with Cercopagis population maxima (Fig. 5).

\section{Predation experiments and energetic requirements}

Laboratory experiments provided corroborative evidence that $C$. pengoi preyed on the two dominant Cladocera, B. longirostris and D. retrocurva. Clear evidence of predation (e.g. detached heads or postabdomen) was often evident in trials involving Daphnia and Bosmina. Cercopagis pengoi consumption rates on Bosmina and Daphnia averaged 2.8 Cercopagis $^{-1}$ day $^{-1}$ (Table 4). This value closely approximates the bioenergetic model estimate for $D$. retrocurva (2.1-4.7 Cercopagis $^{-1} \mathrm{day}^{-1}$ ) but is lower than the estimate $\left(7.1\right.$ Cercopagis $^{-1} \mathrm{day}^{-1}$ ) for B. longirostris (Table 4).

We estimated the daily consumption demand of C. pengoi by multiplying the estimated consumption need of an individual, determined from Yurista \& Schulz (1995), by zooplankton abundance (e.g. Fig. 6). At the offshore location in 1999 and 2000, consumption demand of the $C$. pengoi population exceeded production of the major cladoceran and cycloploid copepod taxa 55 and $65 \%$, respectively, of the time (Fig. 3). In 1999, for example, offshore consumption of $C$. pengoi exceeded production of $D$. retrocurva, $B$. longirostris and D. thomasi during August and September, and extended into October for B. longirostris (Fig. 3). During 2001, offshore consumption exceeded production of these three taxa only $23 \%$ of the time. There were similar patterns of nearshore consumption and production (Fig. 4). Calculated values of the overall impact of $C$. pengoi on the zooplankton community were high at the offshore and nearshore stations in 1999, substantially lower in 2000, and were nearly undetectable in 2001 (Table 5). 
Table 2 Instantaneous birth rate of Daphnia retrocurva and Bosmina longirostris prior to and during the Cercopagis pengoi abundance peak at the offshore station in 1999-2001

\begin{tabular}{llll}
\hline & Date & $\begin{array}{l}\text { Daphnia } \\
\text { retrocurva }\end{array}$ & $\begin{array}{l}\text { Bosmina } \\
\text { longirostris }\end{array}$ \\
\hline 1999 & & & \\
Prior to peak & 8 July & 0.326 & 0.012 \\
& 22 July & 0.267 & 0.021 \\
& 30 July & 0.323 & 0.017 \\
& Average & 0.305 & 0.017 \\
During peak & 5 August & 0.365 & 0.011 \\
& 12 August & 0.334 & 0.008 \\
& 19 August & 0.316 & 0.014 \\
& 25 August & 0.288 & 0.002 \\
2000 & Average & 0.326 & 0.009 \\
Prior to peak & 12 July & 0.274 & 0.000 \\
& 19 July & 0.224 & 0.009 \\
& 27 July & 0.331 & 0.004 \\
During peak & Mean & 0.276 & 0.004 \\
& 3 August & 0.216 & 0.010 \\
& 10 August & 0.318 & 0.025 \\
& 19 August & 0.359 & 0.011 \\
& 24 August & 0.275 & 0.012 \\
2001 & 30 August & 0.266 & 0.017 \\
& Average & 0.287 & 0.015 \\
& & & \\
& 17 July & 0.394 & 0.016 \\
& 25 July & 0.432 & 0.017 \\
& 1 August & 0.407 & 0.008 \\
& Average & 0.411 & 0.014 \\
& 8 August & 0.357 & 0.011 \\
& 15 August & 0.203 & 0.014 \\
& Average & 0.280 & 0.012 \\
\hline
\end{tabular}

\section{Discussion}

Cercopagis pengoi is restricted to the epilimnion and apparently does not migrate below the thermocline in Lake Ontario. Ojaveer et al. (2001) also noted that the
Table 3 Instantaneous birth rate of Daphnia retrocurva and Bosmina longirostris prior to and during the Cercopagis pengoi abundance peak at the nearshore station in 2001

\begin{tabular}{llll}
\hline & Date & $\begin{array}{l}\text { Daphnia } \\
\text { retrocurva }\end{array}$ & $\begin{array}{l}\text { Bosmina } \\
\text { longirostris }\end{array}$ \\
\hline Prior to peak & 26 June & 0.235 & 0.000 \\
& 13 July & 0.261 & 0.008 \\
17 July & 0.311 & 0.020 \\
During peak & Average & 0.269 & 0.010 \\
& 25 July & 0.432 & 0.010 \\
& 1 August & 0.370 & 0.010 \\
& 8 August & 0.361 & 0.011 \\
& 15 August & 0.322 & 0.010 \\
& 22 August & 0.178 & 0.010 \\
& 29 August & 0.259 & 0.011 \\
& Average & 0.320 & 0.010 \\
\hline
\end{tabular}

majority of individuals in Lake Ontario was found within the warm uppermost $20 \mathrm{~m}$ of water both by day and night, with no evidence of diurnal vertical migration. These results contrast with those from the Caspian Sea, where vertical migration into deeper water has been reported (Rivier, 1998). This difference in behaviour may reflect differences in the genetic composition of the Caspian and Lake Ontario populations (Cristescu et al., 2001; Makarewicz et al., 2001a).

In the laboratory, $C$. pengoi preyed on $D$. retrocurva and $B$. longirostris. Predation rates of $D$. retrocurva determined experimentally were similar to those calculated from bioenergetic modelling, while experimental estimates for $B$. longirostris were lower than those from bioenergetic modelling. Consumption rates may be low in our experiments, as prey organisms caught in the surface film may not be readily available to predators.
Fig. 5 Seasonal abundance of Cercopagis pengoi and herbivorous Cladocera (Bosmina, Daphnia, Holopedium) and chlorophyll $a$ concentration at the offshore location, 1999-2001. Please note scale changes.
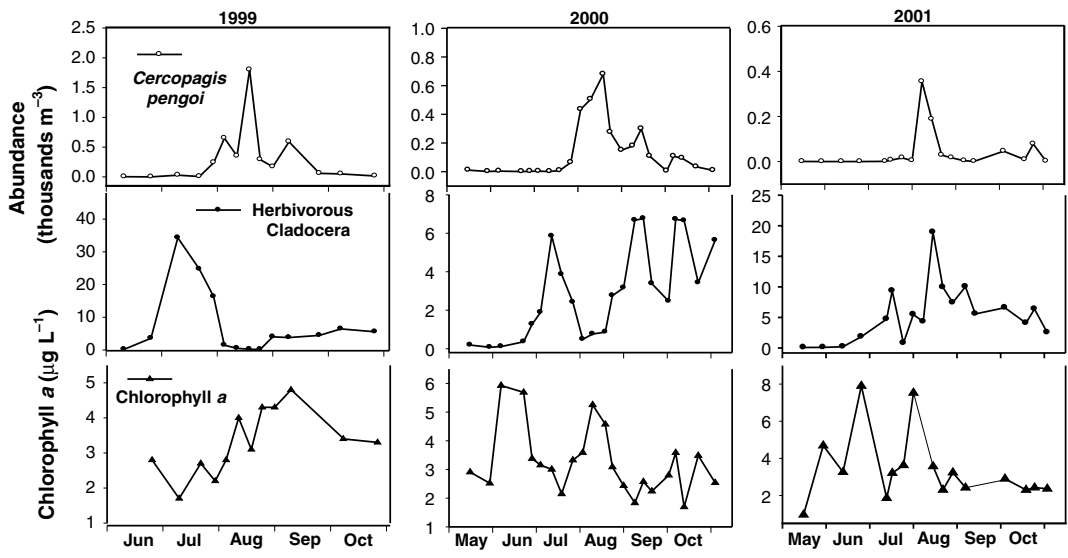
Table 4 Laboratory determined and bioenergetics derived consumption rates of Cercopagis pengoi on dominant Lake Ontario cladoceran zooplankton

\begin{tabular}{|c|c|}
\hline & $\begin{array}{l}\text { Consumption rate } \\
\text { (Number Cercopagis }^{-1} \text { day }^{-1} \text { ) }\end{array}$ \\
\hline \multicolumn{2}{|l|}{ Laboratory } \\
\hline Daphnia retrocurva & 2.8 \\
\hline Bosmina longirostris & 2.8 \\
\hline \multicolumn{2}{|l|}{ Bioenergetic } \\
\hline Daphnia retrocurva* & 4.7 \\
\hline Daphnia retrocurva $^{+}$ & 2.1 \\
\hline Bosmina longirostris* & 7.5 \\
\hline Bosmina longirostris $^{\dagger}$ & 7.1 \\
\hline
\end{tabular}

*Weight calculated from the length-weight relationship developed for Lake Ontario zooplankton (Johannsson \& O'Gorman, 1991) based on length data from this study.

tBased on the median length and length-weight relationships of Great Lakes' species (Culver et al., 1985).

Cercopagis pengoi predation rates based on bioenergetic modelling indicate that abundance of this exotic predator could sharply reduce much of the Lake
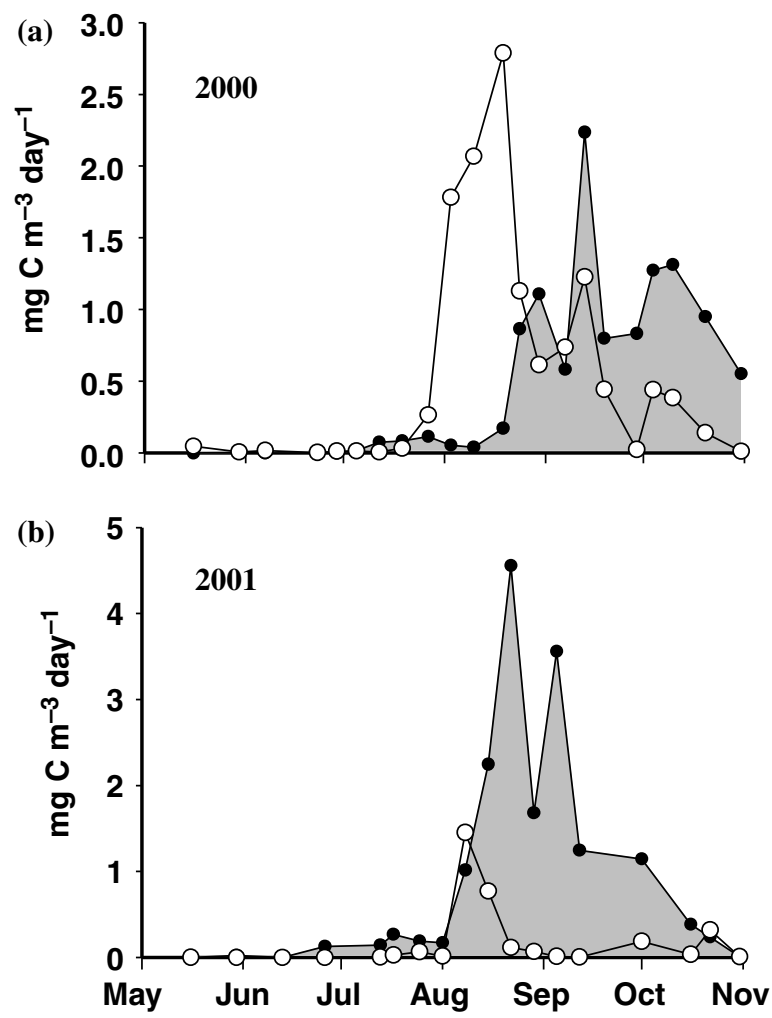

Fig. 6 Daily consumption demand of Cercopagis pengoi (open circles) and daily production of herbivorous cladocerans (filled area) at the offshore location of Lake Ontario in 2000 (a) and 2001 (b). Cercopagis consumption was estimated from the bioenergetics model of Yurista \& Schulz (1995).
Table 5 Predatory Impact (I) of Cercopagis pengoi on the zooplankton community of Lake Ontario during the periods of peak abundance from 1999 to 2001

\begin{tabular}{lcc}
\hline Station & Year & Impact $(I)$ \\
\hline Offshore & 1999 & 0.85 \\
& 2000 & 0.02 \\
& 2001 & $<0.001$ \\
Nearshore & 1999 & 0.73 \\
& 2000 & 0.06 \\
& 2001 & $<0.001$ \\
\hline
\end{tabular}

The parameter $(I)$ is a dimensionless value that varies in the range $0-1$, from no to high predatory impact (Telesh et al., 2001; also see Methods).

Ontario crustacean population within a few days. This result is consistent with both the seasonal and the long-term (pre- and post-invasion) Lake Ontario data. For example, the abundance of Daphnia, Bosmina and Diacyclops was low whenever $C$. pengoi abundance was high, although these prey species often maintained high birth rates. Conversely, high prey abundance typically occurred only when $C$. pengoi was absent or scarce $\left(<200 \mathrm{~m}^{-3}\right.$; Fig. 7$)$.

Historical data are consistent with the hypothesis of predatory suppression of major zooplankton taxa in Lake Ontario. A comparison of zooplankton abundance, pre- and post- $C$. pengoi invasion, indicates that the August abundance of the dominant Lake Ontario zooplankton (D. retrocurva, B. longirostris and $D$. thomasi) has declined significantly after the invasion. A similar result has been observed in the Gulfs of Riga and Finland in the Baltic Sea, where abundances of herbivorous cladocerans (Bosmina spp., Daphnia spp.) and rotifers declined significantly after C. pengoi invaded that basin (Ojaveer et al., 2000; Telesh et al., 2001). Overall, the calculated impact (I) of C. pengoi on the herbivorous zooplankton community was greatest in 1999, when C. pengoi was very abundant, and declined progressively in 2000 and 2001 when $C$. pengoi abundance was much lower (Table 5).

Observed interannual and seasonal changes in herbivorous crustacean abundances may be attributable, in part, to artifacts of the sampling design rather than to the effect of a new predator in the system. However, we are aware of no data that support this scenario for either D. retrocurva or B. longirostris in Lake Ontario. In fact, our studies on Lake Ontario suggest the opposite. The dominant Lake Ontario Cladocera, $B$. longirostris and D. retrocurva, were restricted to the 


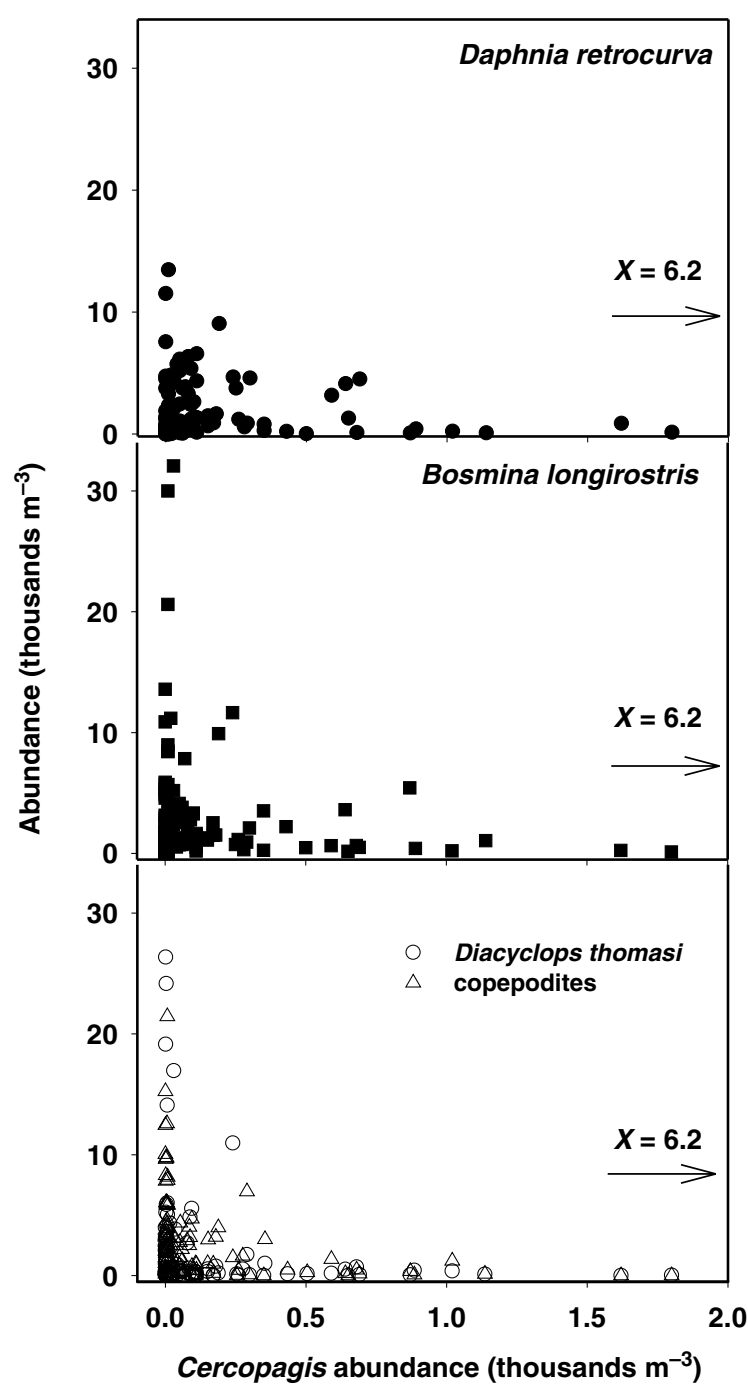

Fig. 7 Simultaneous abundance of Cercopagis pengoi and Daphnia retrocurva, Bosmina longirostris, Diacyclops thomasi and copepodites in Lake Ontario between 1999 and $2001(n=111)$. The highest value of Cercopagis abundance $\left(X=6200 \mathrm{~m}^{-3}\right.$, represented by the arrow) was left off of the graph to improve resolution at the majority of data points; corresponding abundance values of other zooplankton were: $60 \mathrm{~m}^{-3}$ for D. retrocurva; $180 \mathrm{~m}^{-3}$ for B. longirostris; and 100 and $0 \mathrm{~m}^{-3}$ for D. thomasi and copepodites, respectively.

upper $20 \mathrm{~m}$ of Lake Ontario throughout the summer of 2001 (Table 1).

Unlike Bosmina and Daphnia, the majority of the Lake Ontario Diacyclops population resided below the upper $20 \mathrm{~m}$ on five of eight sampling dates during 2001 (Table 1). This observation may be a result of a preference for deeper water during summer stratification (Wilson \& Roff, 1973) or a diurnal vertical migration pattern deeper than that of the Cladocera
(Barbierio, Schact \& Dimartino, 2000). Alternatively, this pattern may be a direct response to predation from C. pengoi, whether it be consumption of individuals in the epilimnion or predator avoidance (Benoit et al., 2002). Clearly, the abundance of $D$. thomasi in Lake Ontario is influenced by several factors, including predation by C. pengoi (Benoit et al., 2002, this study) and by thermal structure. For example, on 19 August 1999 at the offshore site, D. thomasi abundance was $<30 \mathrm{~m}^{-3}$ in the upper $20 \mathrm{~m}$. The following week on 25 August an upwelling event reduced the thickness of the epilimnion from 20 to $4 \mathrm{~m}$ (Makarewicz et al., 2001a). On that day, D. thomasi abundance in the upper $20 \mathrm{~m}$ of the lake increased by a factor of 300, only to decrease again the following week (Fig. 3) when the upwelling event ended. Major changes in Daphnia and Bosmina abundance were not observed with variation in the thermal structure.

Changes in the abundance of Cladocera may have been related to the increase, beginning in 1994, of the planktivorous three-spine stickleback [Gasterosteus aculeatus (Linneaus)] population in Lake Ontario (Hangelin \& Vuorinrn, 1988; Ibrahim \& Huntingford, 1989; Bolger, Bracken \& Dauod, 1990). Stickleback abundance peaked in 1996 and decreased thereafter prior to C. pengoi invading the system in 1998 (Owens et al., 2002). Sticklebacks in Lake Ontario are generally associated with the nearshore, but some individuals will disperse into the pelagic zone and congregate in the metalimnion (Manzer, 1976; R. O'Gorman, pers. comm.). Although we cannot completely dismiss the impact of sticklebacks on the zooplankton community, its presence in the metalimnion and decline in numbers, prior to the decrease in herbivorous cladoceran, suggests that it was not responsible for observed changes in abundances of dominant epilimnetic Cladocera.

Our seasonal and interannual data indicate a strong but variable top-down effect of $C$. pengoi on Lake Ontario's zooplankton community. Microzooplankton in this lake have historically accounted for between 70 and $90 \%$ of phytoplankton consumption (Lampman \& Makarewicz, 1999). Consequently, if microzooplankton are suppressed by $C$. pengoi, an increase in phytoplankton biomass might be anticipated. In 1999 and 2000, when consumption rates of $C$. pengoi greatly exceeded production rates from major herbivorous cladocerans (e.g. Fig. 6a), phytoplankton populations peaked in mid-summer (Fig. 5). During August 2000, 
the edible size fraction of phytoplankton $[<10 \mu \mathrm{m}$ greatest axial linear dimension (GALD)] of the herbivorous cladocerans, comprised approximately 52\% portion of the Lake Ontario phytoplankton community. Phytoplankton composition data was not available in 1999. Significant inverse relationships between herbivorous Cladocera and chlorophyll concentrations were observed in 1999 and 2000, but not 2001. In 2001, when maximum C. pengoi populations were approximately 20 and $65 \%$ lower than their maxima in 1999 and 2000, respectively, and C. pengoi consumption rates were low compared with production of herbivorous cladocerans (Fig. 6b), a response in the phytoplankton population was not apparent. Cercopagis predation on crustacean zooplankton populations in Lake Ontario, especially on Bosmina and Daphnia, thus appear to cascade down the food web to increase phytoplankton abundance. This observation does not rule out the potentially important role that protozoans and rotifers may play in controlling phytoplankton (Vanderploeg et al., 2002), as our sampling scheme did not include these organisms.

Cercopagis pengoi has the ability to reduce dramatically the summer abundance of Lake Ontario zooplankton. Thus, it may be a competitor with planktivorous fish for energy obtained from zooplankton, potentially inducing a significant bottleneck to productivity of the fish community. For example, if the long caudal appendage of $C$. pengoi reduces its vulnerability to fish planktivory, then competition for zooplankton may result in less food for developing fish and produce a bottleneck in recruitment (Shuter \& Mason, 2001). Even if zooplankton production can pass to fish through C. pengoi, fish production may ultimately decline because of lengthening of the food web (i.e. a reduced ecological efficiency). Alternatively, production of some fish species which exploit Cercopagis may increase, as has happened in the Gulf of Riga (Ojaveer et al., 2000). Further investigation on feeding behaviour of planktivores on the introduced Cercopagis is warranted.

In summary, field, laboratory, bioenergetic and physiologic data support the contention that $C$. pengoi feeds on and suppresses abundances of small-bodied herbivorous zooplankton in Lake Ontario. During periods when Cercopagis effectively suppresses other zooplankton, phytoplankton abundance increases proportionally.

\section{Acknowledgments}

Funding support was provided by the New York Sea Grant Institute, the Great Lakes National Program of the U.S. Environmental Protection Agency and the Russian Foundation for Basic Research (No. 01-0449560). W.G. Sprules provided valuable comments, while D. MacNeil and R. O'Gorman provided critical information; we gratefully acknowledge their assistance and advice.

\section{References}

Balcer M.D., Korda N.L. \& Dodson S.I. (1984) Zooplankton of the Great Lakes. The University of Wisconsin Press, Madison, Wisconsin.

Barbierio R.P., Schact L.L. \& Dimartino M.A. (2000) Effects of the vertical distribution of zooplankton on the estimation of abundance and biovolume using deep and shallow tows Report to the Environmental Protection Agency. http://www.epa.gov/glnpo/ monitoring/zooplankton/index.html.

Benoit H.P., Johannsson O.E., Warner D., Sprules W.G. \& Rudstam L. (2002) Assessing the impact of a recent predatory invader: the population dynamics, vertical distribution and potential prey of Cercopagis pengoi in Lake Ontario. Limnology and Oceanography, 40, 626-635.

Bolger T., Bracken J.J. \& Dauod H. (1990) The feeding relationships of brown trout, minnow and threespined stickleback in an upland reservoir system. Hydrobiologia, 208, 169-185.

Brandl Z. \& Fernando C.H. (1975) Investigation on the feeding of carnivorous cyclopoids. Verhandlungen der Internationale Vereinigung für Theoretische und Angewandte Limnologie, 19, 2959-2965.

Charlebois P.M., Raffenberg M.J. \& Dettmers J.M. (2001) First occurrence of Cercopagis pengoi in Lake Michigan. Journal of Great Lakes Research, 27, 258-261.

Cooley J.M., Moore J.E. \& Geiling W.T. (1986) Population dynamics, biomass, and production of the macrozooplankton in the Bay of Quinte during changes in phosphorus loadings. In: Project Quinte: Point Source Phosphorus Control and Ecosystem Response in the Bay of Quinte, Lake Ontario. (Eds C.K. Minns, D.A. Hurley \& K.H. Nicholls), pp. 166167. Canadian Special Publications Fishery Aquatic Sciences, No. 86.

Cristescu M., Hebert P.D.N., Witt J., MacIsaac H.J. \& Grigorovich I.A. (2001) An invasion history for Cercopagis pengoi based on mitochondrial gene sequences. Limnology and Oceanography, 46, 224-229. 
Culver D.A., Boucherle M.M., Bean D.J. \& Fletcher J.W. (1985) Biomass of freshwater crustacean zooplankton from length weight regressions. Canadian Journal of Fisheries and Aquatic Sciences, 42, 1380-1390.

Dermott R.M., Munawar M., Witzil L. \& Ryan P. (1999) An assessment of food web changes in eastern Lake Erie: impact of Dreissena spp. and phosphorus management on rainbow smelt Osmerus mordax. In: State of Lake Erie - Past, Present, and Future (Eds M. Munawar, T. Edsall, \& I.F. Munawar), pp. 367-386. Backhuys, Leiden.

Dumitru C., Sprules W.G. \& Yan N.D. (2001) Impact of Bythotrephes longimanus on zooplankton assemblages of Harp Lake, Canada: an assessment based on predator consumption and prey production. Freshwater Biology, 46, 241-251.

Edmondson W.T. (1959) Freshwater Biology. John Wiley \& Sons, Inc, New York.

Gannon J.E. (1971) Two counting cells for the enumeration of zooplankton microcrustacea. Transactions of the American Microscopical Society, 90, 486-490.

Hangelin C. \& Vuorinrn I. (1988) Food selection in juvenile three-spined sticklebacks in relation to size, abundance and biomass of prey. Hydrobiologia, 157, 169-177.

Ibrahim A.A. \& Huntingford F.A. (1989) Laboratory and field studies on diet choice in three-spined sticklebacks, Gasterosteus aculeatus L., in relation to profitability and visual features of prey. Journal of Fish Biology, 34, 245-257.

Johannsson O.E. \& O'Gorman R. (1991) Roles of predation, food and temperature in structuring the epilimnetic zooplankton populations in Lake Ontario, 1981-1986. Transactions of the American Fishery Society, 120, 193-208.

Johannsson O.E., Mills E.L. \& O'Gorman R. (1991) Changes in the nearshore and offshore zooplankton communities in Lake Ontario, 1981-1988. Canadian Journal of Fisheries and Aquatic Sciences, 48, 1546-1557.

Johannsson O.E., Millard E.S., Ralph K.M., Myles D.D., Graham D.M., Taylor W.D., Giles B.G. \& Allen R.E. (1998) The changing pelagia of Lake Ontario (1981 to 1995): a report of the DFO Long-Term Biomonitoring (Bioindex) Program. Canadian Technical Report Fishery and Aquatic Sciences, No 2243.

Lampman G.G. \& Makarewicz J.C. (1999) The phytoplankton zooplankton link in the Lake Ontario food web. Journal of Great Lakes Research, 25, 239-249.

Lehman J.T. \& Caceres C.E. (1993) Food-web responses to species invasion by a predatory invertebrate: Bythotrephes in Lake Michigan. Limnology and Oceanography, 38, 879-891.

MacIsaac H.J., Grigorovich I.A., Hoyle J.A., Yan N.D. \& Panov V.E. (1999) Invasion of Lake Ontario by the
Ponto-Caspian predatory cladoceran Cercopagis pengoi. Canadian Journal of Fisheries and Aquatic Sciences, 56, 1-5.

Makarewicz J.C. (1991) Feasibility of shore side monitoring of the Great Lakes. Journal of Great Lakes Research, 17, 344-360.

Makarewicz J.C. \& Likens G.E. (1979) Structure and function of the zooplankton community of Mirror Lake, New Hampshire. Ecological Monographs, 49, 109127.

Makarewicz J.C., Bertram P. \& Lewis T.W. (1998) Changes in phytoplankton composition size -class abundance and species composition coinciding with changes in water chemistry and zooplankton community structure of Lake Michigan, 1983 to 1992. Journal of Great Lakes Research, 24, 637-657.

Makarewicz J.C., Grigorovich I.A., Mills E.L. et al. (2001a) Distribution, fecundity and genetics of Cercopagis pengoi (Ostroumov) (Crustacea, Cladocera) in Lake Ontario. Journal of Great Lakes Research, 27, 19-32

Makarewicz J.C., Grigorovich I.A., Mills E.L. et al. (2001b) Erratum. Journal of Great Lakes Research, 27, 262.

Makarewicz J.C., Damske B.T., Laxson C.L., MacIsaac H.J. \& Grigorovich I.A. (2002) Seasonal and vertical distribution, food web dynamics and contaminant biomagnification of Cercopagis pengoi in Lake Ontario. In: Proceedings of the 10th International Conference on Aquatic Invasive Species, pp. 132-141. Alexandria, PA.

Manzer J.I. (1976) Distribution, food, and feeding of the threespine stickleback, Gasterosteu aculeatus, in Great Central Lake, Vancouver Island, with comments on competition for food with juvenile sockeye salmon, Oncorhynchus nerka. Fishery Bulletin, 74, 647-668.

Mills E.L., Leach J.H., Carlton J.T. \& Secor C.L. (1993) Exotic species in the Great Lakes: a history of biotic crises and anthropogenic introductions. Journal of Great Lakes Research, 19, 1-54.

Monakov A.V. \& Sorokin Y.I. (1972) Some results on investigations on nutrition of water animals. In: Productivity Problems in Freshwaters (Eds J. Kajak \& A. Hillbricht-Ilkowska), pp. 765-733. Polish Scientific Publishers, Krakow.

Mordukhai-Boltovskoi F.D. (1968) Order Cladocera. In: Atlas of Invertebrates of the Caspian Sea (Eds Y.A. Birshtein, L.G. Vinogradov, N.N. Kondakov, M.S. Astakhova \& N.N. Romanova), pp. 120-160. Pishchevaya Promyshlennost' Press, Moscow, USSR.

O'Gorman R., Bergstedt R.A. \& Eckert T.C. (1987) Prey fish dynamics and salmonine predator growth in Lake Ontario, 1978-84. Canadian Journal of Fisheries and Aquatic Sciences, 44, 390-403.

Ojaveer H., Simms M., Lankov A. \& Lumberg A. (2000) Consequence of invasion of a predatory cladoceran. 
ICES Council Meeting Paper 16. http://www.biodiv. org/doc/case-studies/cs-ais-ee-cladoceran-en.pdf.

Ojaveer H., Kuhns L.A., Barbierio R.P. \& Tuchman M.L. (2001) Distribution and population characteristics Cercopagis pengoi in Lake Ontario. Journal of Great Lakes Research, 27, 10-18.

Owens R.W., O'Gorman R., Eckert T.H. \& Lantry B.F. (2002) The offshore fish community in southern Lake Ontario, 1972-1998. In: The State of Lake Ontario: Past, Present and Future. (Ed. M. Munawar). Ecovision World Monograph Series, Backhuys Publishers, Leiden, The Netherlands.

Paloheimo J.E. (1974) Calculation of instantaneous birth rate. Limnology and Oceanography, 5, 692-694.

Ricciardi A. (2001) Facilitative interactions among aquatic invaders: is an 'invasional meltdown' occurring in the Great Lakes? Canadian Journal of Fisheries and Aquatic Sciences, 58, 2513-2525.

Ricciardi A. \& MacIsaac H.J. (2000) Recent mass invasion of the North American Great Lakes by Ponto-Caspian species. Trends in Ecology and Evolution, 15, 62-65.

Rivier I.K. (1998) The Predatory Cladocera (Onychopoda: Podonidae, Polyphemidae, Cercopagidae) and Leptodorida of the world. Backhuys Publishing, Leiden.

Ryan P.A., Witzel I.D., Paine J.R., Freeman M.J., Hardy M. \& Sztramko K.I. (1999) Recent trends in eastern Lake Erie fish stocks within a changing trophic state and food web (1980-1984). In: State of Lake Erie-Past, Present, and Future. (Eds M. Munawar, T. Edsall \& I.F. Munawar) pp. 241-290. Backhuys Publishing, Leiden.

Salonen K., Sarvala J., Hakala I. \& Viljanen M.L. (1976) The relation of energy and organic carbon in aquatic invertebrates. Limnology and Oceanography, 21, 724-730.

Schulz K.L. \& Yurista P.M. (1999) Implications of an invertebrate predators (Bythotrephes cederstroemi) atypical effects on a pelagic zooplankton community. Hydrobiologia, 380, 179-193.

Shuter B.J. \& Ing K.K. (1997) Factors effecting the production of zooplankton in Lakes. Canadian Journal Fisheries and Aquatic Sciences, 54, 359-377.

Shuter B. \& Mason D.M. (2001) Exotic invertebrates, food web disruption, and lost fish production: understanding impacts of dreissenid and cladoceran invaders on lower lakes fish communities and forecasting invasion impacts on upper lakes fish communities. Report to the Great Lakes Fisheries Commission http://www. foodwebdisruption.org/fweb_whitepaper.pdf.

Siegal S. \& Castellan N.J. (1988). Nonparametric Statistics for the Behavioral Sciences. McGraw Hill, New York.
Simm M. \& Ojaveer H. (1999) Occurrence of different morphological forms of Cercopagis in the Baltic Sea. Proceedings Estonian Academy of Science, Biology, and Ecology, 48, 169-172.

Telesh I.V., Bolshagin P.V. \& Panov V.E. (2001) Quantitative estimation of the impact of the alien species Cercopagis pengoi (Crustacea:Onychopoda) on the structure and functioning of plankton community in the Gulf of Finland, Baltic Sea. Doclady Biological Sciences, 377, 157-159.

Therriault T.W, Grigorovich I.A., Kane D.D., Haas E.M., Culver D.A. \& MacIsaac H.J. (2002) Range expansion of the exotic zooplankter Cercopagis pengoi (Ostroumov) into western Lake Erie and Muskegon Lake. Journal of Great Lakes Research, 28, 698-701.

Urabe J. (1991) Effect of food concentration on the carbon balance of Bosmina longirostris (Crustacea: Cladocera). Freshwater Biology, 26, 57-68.

Vanderploeg H.A., Nalepa T.F., Jude D.J., Mills E.L., Holeck K.T., Liebig J.R., Grigorovich I.A. \& Ojaveer, H. (2002) Dispersal and emerging ecological impacts of Ponto-Caspian species in the Laurentian Great Lakes. Canadian Journal Fisheries and Aquatic Sciences, 59, 12091228.

Wetzel R.G. \& Likens G.E. (1994) Limnological Analysis. Springer Verlag, New York.

Wilson J.B. \& Roff J.C. (1973) Seasonal vertical distribution and diurnal migration patterns of Lake Ontario crustacean zooplankton. In: Proceedings of 16th Conference on Great Lakes Research. pp. 190-203. International Association of Great Lakes Research.

Yan N.D., Girard R. \& Boudreau S. (2002) An introduced invertebrate predator (Bythotrephes) reduces zooplankton species richness. Ecology Letters, 5, 481-485.

Yurista P.M. (1992) Embryonic and post-embryonic development in Bythotrephes cederstroemi. Canadian Journal of Fisheries and Aquatic Sciences, 49, 1118-1125.

Yurista P.M. \& Schulz K.L. (1995) Bioenergetics analysis of prey consumption by Bythotrephes cederstroemi in Lake Michigan. Canadian Journal of Fisheries and Aquatic Sciences, 52, 141-150.

Zar, H.J. (1999). Biostatistical Analysis, 4th edn. Prentice Hall, New Jersey.

Zozulya S.S. (1977) Peculiarities of the first Bythotrephes generation hatched from the latent eggs. Byulyuten Instituta Biologii Vnutrennikh Vod 33, 34-38. [in Russian].

(Manuscript accepted 29 August 2003) 